\title{
An outbreak of acute respiratory infection at a training base in Beijing, China due to human adenovirus type B55
}

Guilan Lu', Xiaomin Peng ${ }^{1}$, Renqing Li', Yimeng Liu', Zhanguo Wu², Xifeng Wang ${ }^{2}$, Daitao Zhang ${ }^{1}$, Jiachen Zhao ', Ying Sun ${ }^{1}$, Li Zhang ${ }^{1}$, Peng Yang ${ }^{1}$ and Quanyi Wang ${ }^{1 *}$

\begin{abstract}
Background: Twelve students experienced symptoms of acute respiratory infection (ARI) at a training base in Beijing from August 26 to August 30, 2015. We investigated the cause of this ARI outbreak.

Methods: In partnership with the local center for disease control, we collected a total of twelve pharyngeal swab specimens as well as demographic information for the affected patients. We used multiplex real-time PCR to screen for sixteen common respiratory viruses in these samples. To isolate HAdV, we inoculated Hep-2 cells with the human adenovirus (HAdV)-positive samples and then carried out sequencing and phylogenetic analysis of the hexon, fiber, and penton genes of the isolated adenoviruses. In addition, we analyzed the entire genome of one strain isolated from the index case to identify single-nucleotide substitutions.

Results: We identified ten HAdV-positive students using multiplex real-time PCR. None of the students were coinfected with other viruses. We successfully isolated seven HAdV strains from the pharyngeal swab specimens. The coding sequences of the hexon, fiber, and penton genes of these seven HAdV strains were identical, suggesting that they represented seven strains from a single virus clone. One HAdV isolate obtained from the index case, BJDX-01-2015, was selected for whole genome analysis. From this isolate, we obtained a 34,774-nucleotide sequence. The genome of BJDX-01-2015 clustered with HAdV-B55 in phylogenetic analyses and had $99.97 \%$ identity with human adenovirus 55 isolate HAdV-B/CHN/BJ01/2011/55 (GenBank accession no. JX491639).

Conclusions: We identified HAdV-B55 as the strain associated with the August 2015 ARI outbreak at a training base in Beijing. This was the first reported outbreak in Beijing due to HAdV-B55. Continuous surveillance of respiratory adenoviruses is urgently needed to understand the epidemiological and evolutionary features of HAdV-B55, and an epidemiological modeling approach may provide further insights into this emerging public health threat. Furthermore, the clinical laboratory data from this outbreak provides important reference for the clinical diagnosis and may ultimately aid in informing the development of strategies to control and prevent respiratory tract infections caused by HAdV-B55.
\end{abstract}

Keywords: Outbreak, Human adenovirus, Acute respiratory infection, Phylogenetic analysis, Whole genome sequencing

\footnotetext{
* Correspondence: bjcdcxm@126.com

${ }^{1}$ Institute for Infectious Disease and Endemic Disease Control, Beijing Center for Disease Prevention and Control, Beijing Research Center for Preventive Medicine, 16\# He Ping Li Middle Street, Dongcheng District, Beijing 100013, China

Full list of author information is available at the end of the article
}

(c) The Author(s). 2020 Open Access This article is licensed under a Creative Commons Attribution 4.0 International License, which permits use, sharing, adaptation, distribution and reproduction in any medium or format, as long as you give appropriate credit to the original author(s) and the source, provide a link to the Creative Commons licence, and indicate if changes were made. The images or other third party material in this article are included in the article's Creative Commons licence, unless indicated otherwise in a credit line to the material. If material is not included in the article's Creative Commons licence and your intended use is not permitted by statutory regulation or exceeds the permitted use, you will need to obtain permission directly from the copyright holder. To view a copy of this licence, visit http://creativecommons.org/licenses/by/4.0/. The Creative Commons Public Domain Dedication waiver (http://creativecommons.org/publicdomain/zero/1.0/) applies to the data made available in this article, unless otherwise stated in a credit line to the data. 


\section{Background}

Human adenoviruses (HAdVs) cause a wide variety of clinical manifestations, including respiratory tract infection, gastroenteritis, kerato-conjunctivitis, acute hemorrhagic cystitis, nephritis, hepatitis, and encephalitis [1-3]. HAdVs are responsible for $2-5 \%$ of all respiratory illnesses and for $4-10 \%$ of pneumonias in children $[4,5]$. Most HAdV infections are mild, self-limiting, and indistinguishable from other viral infections. However, the illnesses caused by HAdVs can be severe or even fatal and can result in substantial morbidity $[6,7]$. Outbreaks of HAdV-associated acute respiratory infection (ARI) usually occur in healthy children or in adults in enclosed or crowded settings $[1,8]$.

HAdV was first reported as a viral pathogen in 1953 [6]. Since this initial identification, HAdVs have been classified into seven species (A to G), and the Human Adenovirus Working Group has identified 90 HAdV types as of July 2018 (http://hadvwg.gmu.edu/) [7-12]. Adenoviruses are non-enveloped icosahedral particles that contain linear double-stranded DNA genomes with sizes ranging from 26 to $45 \mathrm{~kb}$. Adenovirus genomes are characterized by inverted terminal repeat sequences (ITRs) with sizes ranging from 36 to over $200 \mathrm{bp}$ [12]. The HAdV viral capsid, which surrounds the genome, is composed of three major proteins: hexon, penton base, and fiber [13].

Different HAdV species display various tissue tropisms that correlate with the different clinical symptoms of infection [14]. HAdV species A has often been associated with the gastrointestinal tract, whereas species $\mathrm{B}$ (HAdV-3, 7, 14, and 55), C (HAdV-1, 2, 5, and 6), and $\mathrm{E}$ (HAdV-4) are known to cause respiratory tract infections. Species D (HAdV-8, 19, and 37) commonly causes adenoviral kerato-conjunctivitis. Species F variants, including HAdV-F40 and-F41, and species $G$ variant HAdV-G52 are mainly associated with gastrointestinal tract infections [2].

HAdVs have been associated with previous outbreaks of ARI. HAdV-B3 and HAdV-B7 cause frequent outbreaks in the United States [15]. In Asia, the prevalence of HAdVs in patients with ARIs has ranged from 0.8 to $11.30 \%$ [16-20]. Recently, Guo et al. (2012) reported that HAdV-B3, HAdV -B7, HAdV -B11, and HAdV -B14 were the most frequently detected virus strains among patients with acute adult adenovirus infections in Beijing from May 2005 to July 2010 [16].

In China, HAdV-B3 and HAdV-B7, two HAdV species $B$ subtypes, are common causes of epidemic ARI outbreaks [21-24]. In 2006, an ARI outbreak occurred in Qishan, Shaanxi Province, China. A re-emergent isolate of HAdV-B55 (QS-DLL), originally described as HAdV11a and fully characterized in 2009, was reported to be the cause of this outbreak [25]. This re-emergent HAdV-B55 was shown to have evolved from a hexon recombination between HAdV-B11 and HAdV-B14 [9, 25]. Since its characterization, HAdV-B55 has been associated with several respiratory infection outbreaks and is known to be responsible for severe respiratory diseases [9, 25-28].

Here we describe an outbreak of ARI caused by HAdV-B55 at a training base in the Daxing District of Beijing, China. To help identify the causative pathogen, we collected pharyngeal swab specimens from the affected students and carried out molecular detection and typing, phylogenic analysis, and whole-genome sequencing. This is the first reported outbreak of ARI in Beijing due to HAdV-B55.

\section{Methods}

\section{The training base where the HAdV-B55 outbreak took place}

On August 31, 2015, local public health authorities were informed about an outbreak of ARI among young students at a training base located in the Daxing District of Beijing. The training base consisted of two three-floor buildings for teaching and three three-floor dormitories with eight persons to a room. The training base recruits only male middle school graduates. Approximately 3000 students majoring in Mathematics, Chinese, and English were enrolled in a total of sixty classes. The training base employs 100 full-time staff members.

\section{Epidemiological investigation}

On August 26, 2015, one student reported symptoms of an ARI and had a body temperature of $38.4^{\circ} \mathrm{C}$. By August 30, a total of 12 ARI patients from the same class were reported by the local hospital. For the purposes of our analysis, we defined ARI cases as individuals with a body temperature over $38.0^{\circ} \mathrm{C}$ and with at least one symptom of a respiratory tract infection, such as cough or sore throat. On August 31, the Daxing District Center for Disease Prevention and Control (CDC) began an epidemiological investigation, collecting demographic, clinical and laboratory data. Under the guidance of the $\mathrm{CDC}$, the training base took precautionary measures, including quarantining the affected students, carrying out a routine cleaning and disinfection of living quarters, and morning body temperature checks. No further new cases were reported by September 08, 2015.

\section{Patients and samples}

Pharyngeal swab samples were obtained from each of the twelve students infected in this ARI outbreak. The specimens were collected in $3 \mathrm{ml}$ vials containing viral transport medium and quickly transported on ice to the laboratory of the Daxing District CDC. The specimens were stored at $-80^{\circ} \mathrm{C}$ until further use. Patient information and laboratory results are shown in Table 1. 
Table 1 Patient information and laboratory results

\begin{tabular}{|c|c|c|c|c|c|c|c|c|c|c|c|c|}
\hline \multirow{2}{*}{$\begin{array}{l}\text { ID } \\
\text { No. }\end{array}$} & \multirow{2}{*}{$\begin{array}{l}\text { Onset date } \\
(\mathrm{m} / \mathrm{d} / \mathrm{y})\end{array}$} & \multirow{2}{*}{$\begin{array}{l}\text { Specimen Collection } \\
\text { date }(\mathrm{m} / \mathrm{d} / \mathrm{y})\end{array}$} & \multicolumn{10}{|c|}{ Clinical symptoms } \\
\hline & & & $\begin{array}{l}\text { Body } \\
\text { temperature } \\
\left({ }^{\circ} \mathrm{C}\right)\end{array}$ & Cough & $\begin{array}{l}\text { Sore } \\
\text { throat }\end{array}$ & $\begin{array}{l}\text { Body } \\
\text { aches }\end{array}$ & Headache & $\begin{array}{l}\text { Nasal } \\
\text { congestion }\end{array}$ & Rhinorrhea & $\begin{array}{l}\text { Conjunctival } \\
\text { hyperemia }\end{array}$ & Diarrhea & $\begin{array}{l}\text { White blood } \\
\text { cell count }\left(10^{9} / \mathrm{L}\right.\end{array}$ \\
\hline 1 & 08/26/2015 & $08 / 31 / 2015$ & 38.4 & - & + & + & + & - & - & - & - & 7.8 \\
\hline 2 & $08 / 26 / 2015$ & 08/31/2015 & 39.0 & - & - & + & + & - & - & - & - & 5.2 \\
\hline 3 & 08/27/2015 & $08 / 31 / 2015$ & 38.5 & + & - & - & + & + & - & - & - & 9.1 \\
\hline 4 & 08/28/2015 & 08/31/2015 & 39.5 & - & + & - & + & - & - & - & - & 5.7 \\
\hline 5 & 08/28/2015 & $08 / 31 / 2015$ & 39.6 & - & + & + & + & + & - & - & - & 7.0 \\
\hline 6 & 08/29/2015 & $08 / 31 / 2015$ & 40.0 & + & + & - & + & - & - & - & + & 5.0 \\
\hline 7 & 08/29/2015 & 08/31/2015 & 38.8 & - & + & - & - & - & - & - & - & 6.4 \\
\hline 8 & 08/30/2015 & 08/31/2015 & 38.2 & - & + & - & + & - & - & - & - & 8.3 \\
\hline 9 & 08/30/2015 & 08/31/2015 & 39.4 & - & - & + & - & - & - & - & - & 9.3 \\
\hline 10 & 08/30/2015 & $08 / 31 / 2015$ & 39.0 & - & + & - & - & - & - & - & - & / \\
\hline 11 & 08/30/2015 & $08 / 31 / 2015$ & 38.6 & - & + & + & + & - & - & - & - & 7.9 \\
\hline 12 & 08/29/2015 & 08/31/2015 & 39.6 & - & + & - & - & - & - & - & - & / \\
\hline
\end{tabular}

ID No. Identification number; +, yes; -, no; /, not tested

\section{Respiratory virus detection}

Nucleic acids were extracted from $140 \mu \mathrm{l}$ of each of the clinical samples using QIAamp Viral RNA mini Kits (Qiagen, Hilden, Germany) according to the manufacturer's instructions. Pharyngeal swab specimens were screened for 16 common respiratory pathogens via realtime PCR multiplex assays using commercial kits (Uninovo Biological Technology, Zhenjiang, China) as described by Shi W., et al. [29]. The 16 pathogens assayed using this approach were influenza virus A (H3), pandemic influenza virus A (H1N1), influenza viruses A and $\mathrm{B}$ (Flu A and B), parainfluenza viruses 1, 2, 3, and 4 (PIV1, 2, 3, and 4), human metapneumovirus (hMPV), human bocavirus (HBoV), human coronavirus OC43/ NL63, 229E/ HKU1, human respiratory syncytial virus (HRSV), human rhinovirus (HRhV), and HAdV.

\section{HAdV isolation and typing}

Hep-2 cells were inoculated with HAdV PCR-positive specimens and cultured in high-glucose Dulbecco's Modified Eagle Medium (Gibco, NY, USA) containing $2 \%$ fetal bovine serum (Gibco, NY, USA), $100 \mathrm{U} / \mathrm{mL}$ penicillin (Gibco, NY, USA), and $100 \mathrm{mg} / \mathrm{mL}$ streptomycin (Gibco, NY, USA) at $37^{\circ} \mathrm{C}$ in a $5 \% \mathrm{CO}_{2}$ incubator for 1 week following standard protocols [25]. The cultured cells were checked regularly for cytopathic effects (CPE) and harvested when cytopathic effects (CPE) were observed. Cultures with CPE were screened for specific HAdVs as described by Kim C et al. [30].

Molecular typing of HAdVs was performed via conventional PCR using specific primers targeting the complete coding sequences of the hexon, fiber, and penton genes [31]. Viral DNA was extracted from cultured medium using QIAamp RNA mini kits (Qiagen, Hilden,
Germany) according to the manufacturer's instructions [32]. Conventional PCR was conducted using highfidelity DNA polymerase (Takara, Dalian, China) according to the manufacturer's instructions. The hexon, fiber, and penton genes of HAdV were amplified as described previously [31]. For the hexon and penton genes, the PCR protocol was: $94^{\circ} \mathrm{C}$ for $5 \mathrm{~min}$., followed by 35 cycles of $50 \mathrm{~s}$. at $94{ }^{\circ} \mathrm{C}, 50 \mathrm{~s}$. at $55^{\circ} \mathrm{C}, 3 \mathrm{~min}$. at $72^{\circ} \mathrm{C}$, and a final extension step of $72{ }^{\circ} \mathrm{C}$ for $10 \mathrm{~min}$. The PCR protocol for amplification of fiber gene fragments was identical, except for the annealing temperature, which was $52^{\circ} \mathrm{C}$ instead of $55^{\circ} \mathrm{C}$. The amplified PCR products were excised from agarose gels, purified using an Axyprep DNA gel extraction kit (Axygen, Hangzhou, China), and bidirectionally sequenced using the Sanger sequencing method by Invitrogen Biotechnology Co., Ltd. (Invitrogen, Beijing, China) with an ABI 3730 DNA Analyzer (Applied Biosystems, Austin, TX, USA).

\section{Whole-genome sequencing}

To further analyze mutations in the genome sequences of the viruses isolated in this ARI outbreak, we sequenced the whole genome of one isolate from the index case using the Sanger method. Targeted 1-2 $\mathrm{kb}$ segments that covered the entire genome with overlapping sequences of about $200 \mathrm{bp}$ were amplified by PCR. The 5' and 3' ITRs of the genome were amplified and cloned into a plasmid $\mathrm{T}$-vector and then sequenced. A set of 47 pairs of primers was designed in-house to amplify the whole genome according to the reference sequence (GenBank accession no. FJ643676) and then used for separate PCRs. Primer sequences are available upon request. 
Whole-genome sequencing segments were amplified using high-fidelity polymerase (Takara, Dalian, China) using $1.0 \mathrm{mM}$ of each primer. PCRs were carried out using a BioRad thermocycler (Applied Biosystems, Austin, TX, USA) with the following protocol: $94^{\circ} \mathrm{C}$ for $5 \mathrm{~min}$., followed by 35 cycles of $50 \mathrm{~s}$. at $94{ }^{\circ} \mathrm{C}, 50 \mathrm{~s}$. at appropriate annealing temperature for separate primers, $3 \mathrm{~min}$. at $72{ }^{\circ} \mathrm{C}$, and a final extension step of $72{ }^{\circ} \mathrm{C}$ for $10 \mathrm{~min}$.

The amplified segments were purified and bi-directionally sequenced. Gaps and ambiguous sequences were PCRamplified using new primers and re-sequenced. DNA sequence fragments were assembled using the SeqMan program implemented in DNASTAR Lasergene 7.0 (DNAS TAR, Inc. Madison, WI) into a single contig. The genomic sequence determined in this study was deposited in GenBank under accession number MK886831.

\section{Sequence alignment and phylogenetic analysis}

Nucleotide sequence homologies were identified using the Basic Local Alignment Search Tool (BLAST, https://blast. ncbi.nlm.nih.gov/). Multiple nucleotide sequence alignments were performed using the ClustalW program implemented in BioEdit. Comparisons between the whole genome sequence of the BJDX-01-2015 virus strain and those of other types of HAdVs were generated using CLC Genomics Workbench (Qiagen, Hilden, Germany).

Phylogenetic trees were constructed using the maximum likelihood method in the MEGA program (Version 5.05). One thousand bootstrap replications were used to estimate distances. Bootstrap values greater than $70 \%$ are shown for selected nodes in Fig. 2 (a-d). Wholegenome sequences and hexon, fiber, and penton gene sequences from other HAdVs were downloaded from GenBank on April 3, 2019.

\section{Results}

\section{Outbreak description}

On August 26, 2015, a 15-year old male student developed a case of ARI, with a peak body temperature of $38.4^{\circ} \mathrm{C}$. By August 31, a total of 12 male students were infected. No females were infected. The mean age of the infected students was 15.4 years (median, 15 years; range, 14-17 years). The distribution of daily cases is shown in Fig. 1. Reported students were from the same class but living in six different dormitory rooms. The outbreak lasted for 6 days.

\section{Clinical symptoms of the infected students}

The clinical symptoms of the infected students are described in Table 1. All 12 infected individuals had a fever; 9 (75\%) students had a sore throat, and 8(66.67\%) students had a headache. Other symptoms reported by the patients were cough, body ache, stuffy nose, and diarrhea. All affected students had normal white blood counts. Most of the infected students were treated in outpatient clinics; only one patient, who had non-severe pneumonia, was hospitalized.

The index case (ID No.1) was diagnosed as having an upper respiratory infection with a peak temperature of $38.4{ }^{\circ} \mathrm{C}$, a neutrophil count of $72.2 \%$ (normal range, 50$70 \%$ ), percentage of lymphocytes of $22.2 \%$ (normal range, $20-40 \%)$, and white blood cell count of $7.8 \times 10^{9} /$ $\mathrm{L}$ (normal range, 4.0-10.0 × 10 $/ \mathrm{L}$ ).

The hospitalized student (ID No.6) had a peak temperature of $40.0^{\circ} \mathrm{C}$ accompanied by a cough, headache, sore throat, and diarrhea. He had a neutrophil count of $78.6 \%$ (normal range, $50-70 \%$ ), a percentage of lymphocytes of $17.8 \%$ (normal range, $20-40 \%$ ), and a white blood cell count of $5.04 \times 10^{9} / \mathrm{L}$ (normal range, $\left.4.0-10.0 \times 10^{9} / \mathrm{L}\right)$. A chest $\mathrm{x}$-ray showed patchy shadows on the right lung of the hospitalized student.

\section{Multiplex-PCR detection}

A total of 12 respiratory samples were obtained from the 12 students. Ten specimens were shown to be HAdVpositive using multiplex PCR (Uninovo Biological Technology, Jiangshu, China). None of the $10 \mathrm{HAdV}$-positive patients were co-infected with other respiratory viruses.

\section{Virus isolation and HAdV typing}

To isolate viruses, we inoculated Hep-2 cells with the HAdV-positive samples and isolated seven HAdV virus strains. Using typing primers, which allow for the determination of viral type, we sequenced the hexon, fiber, and penton genes in the seven HAdV strains [31].

The hexon (2841 bp), fiber (978 bp), and penton (1674 bp) sequences from the seven HAdV isolates were $100 \%$ identical, suggesting that this outbreak was caused by a single viral strain. We then compared the hexon, fiber, and penton sequences of one of the viral strains isolated from the index case (ID No.1; referred to as BJDX-012015), with other HAdV-B55, HAdV-B11 and HAdV-B14 strains. Based on BLAST analysis, the hexon, fiber, and penton genes were 99.6, 100, and 100\% identical to the genes of the HAdV-B55 reference strain QS-DLL in China (GenBank accession number FJ643676), respectively,. The hexon, fiber, and penton genes were each $100 \%$, identical to the genes of the isolate HAdV-B/CHN/BJ01/2011/55 (GenBank accession no. JX491639; Table 2), which was identified from a single patient in Beijing with severe community-acquired pneumonia (CAP) who was infected with HAdV-B55. One of the seven strains, BJDX-01-2015, was selected for further whole-genome studies.

\section{Whole-genome sequencing}

We obtained and assembled the full genome of the index case isolate, BJDX-01-2015. The sequence of this genome has been deposited in GenBank (accession number MK886831). The complete genome of BJDX-01-2015 


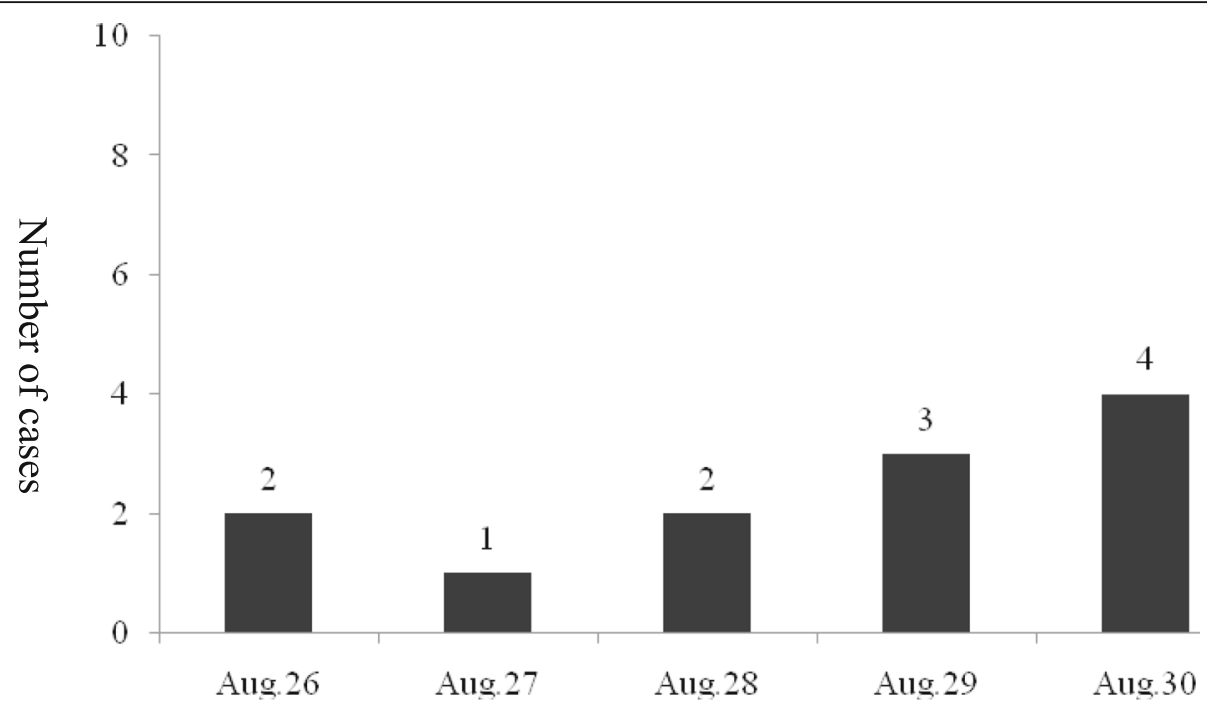

Onset date of cases

Fig. 1 Case distribution during a 2015 outbreak of HAdV-B55 in Beijing. Left Y-axis, number of cases; right Y-axis, onset date of cases

was 34,774 nucleotides in length and had 137-bp inverted terminal repeat sequences in the $5^{\prime}$ - and $3^{\prime}-$ untranslated regions (5'-UTR and $3^{\prime}$-UTR).

\section{Phylogenetic analysis of the HAdV-B55 strain}

To investigate the genetic relationships between isolate BJDX-01-2015 and other HAdV strains, we constructed phylogenetic trees (Fig. $2(\mathrm{a}-\mathrm{d}))$ using the maximum likelihood method based on the complete hexon, fiber, and penton gene sequences of strain BJDX-01-2015 and other HAdV strains. All phylogenetic trees showed that
BJDX-01-2015, associated with this outbreak, clustered with HAdV-B55. The BJDX-01-2015 hexon gene also clustered with HAdV-B11 (GenBank accession number AF532578), while the fiber and penton genes and the full BJDX-01-2015 genome clustered with HAdV-B14 (GenBank accession number AY803294 and JX892927).

Whole-genome alignment and mutation analysis

Comparisons of the whole genome sequence of the BJDX-01-2015 virus strain with other HAdV-B55, HAdV-B11 and HAdV-B14 strains are shown in Fig. 3.

Table 2 Nucleotide identities of BJDX-01-2015 compared with other HAdV-B55, HAdV-B11, and HAdV-B14 strains based on the hexon, fiber and penton genes

\begin{tabular}{|c|c|c|c|c|c|}
\hline Type & Strain name & GenBank accession number & Hexon & Fiber & Penton \\
\hline \multirow[t]{11}{*}{ HAdV55 } & HAdV-B/CHN/BJ01/2011/55 & JX491639 & $100 \%$ & $100 \%$ & $100 \%$ \\
\hline & QS_DLL & FJ643676 & $99.96 \%$ & $100 \%$ & $100 \%$ \\
\hline & CQ-1657 /2011 & $J X 123028$ & $99.96 \%$ & $100 \%$ & $100 \%$ \\
\hline & Shanxi/QZ01/ 2011 & KJ883522 & $99.96 \%$ & $99.90 \%$ & $100 \%$ \\
\hline & Hebei/BD6729/2013 & KJ883521 & $99.96 \%$ & $99.80 \%$ & $99.94 \%$ \\
\hline & SGN1222 & FJ597732 & $99.93 \%$ & $99.90 \%$ & $100 \%$ \\
\hline & Yunnan/ KM04 /2016 & KY002685 & $99.89 \%$ & $99.90 \%$ & $100 \%$ \\
\hline & South Dakota/6380/1997 & FJ841899 & $99.93 \%$ & & \\
\hline & Spain/273/1969 & FJ841900 & $99.58 \%$ & & \\
\hline & South Dakota/6380/1997 & FJ841907 & & $100 \%$ & \\
\hline & Spain/273/1969 & FJ841908 & & $99.90 \%$ & \\
\hline HAdV11 & Slobitski & AF532578 & $98.07 \%$ & $94.39 \%$ & $97.69 \%$ \\
\hline \multirow[t]{2}{*}{ HAdV14 } & de Wit & AY803294 & $92.67 \%$ & $99.59 \%$ & $99.64 \%$ \\
\hline & CHN 2012 & JX892927 & $92.57 \%$ & $99.08 \%$ & $99.64 \%$ \\
\hline
\end{tabular}




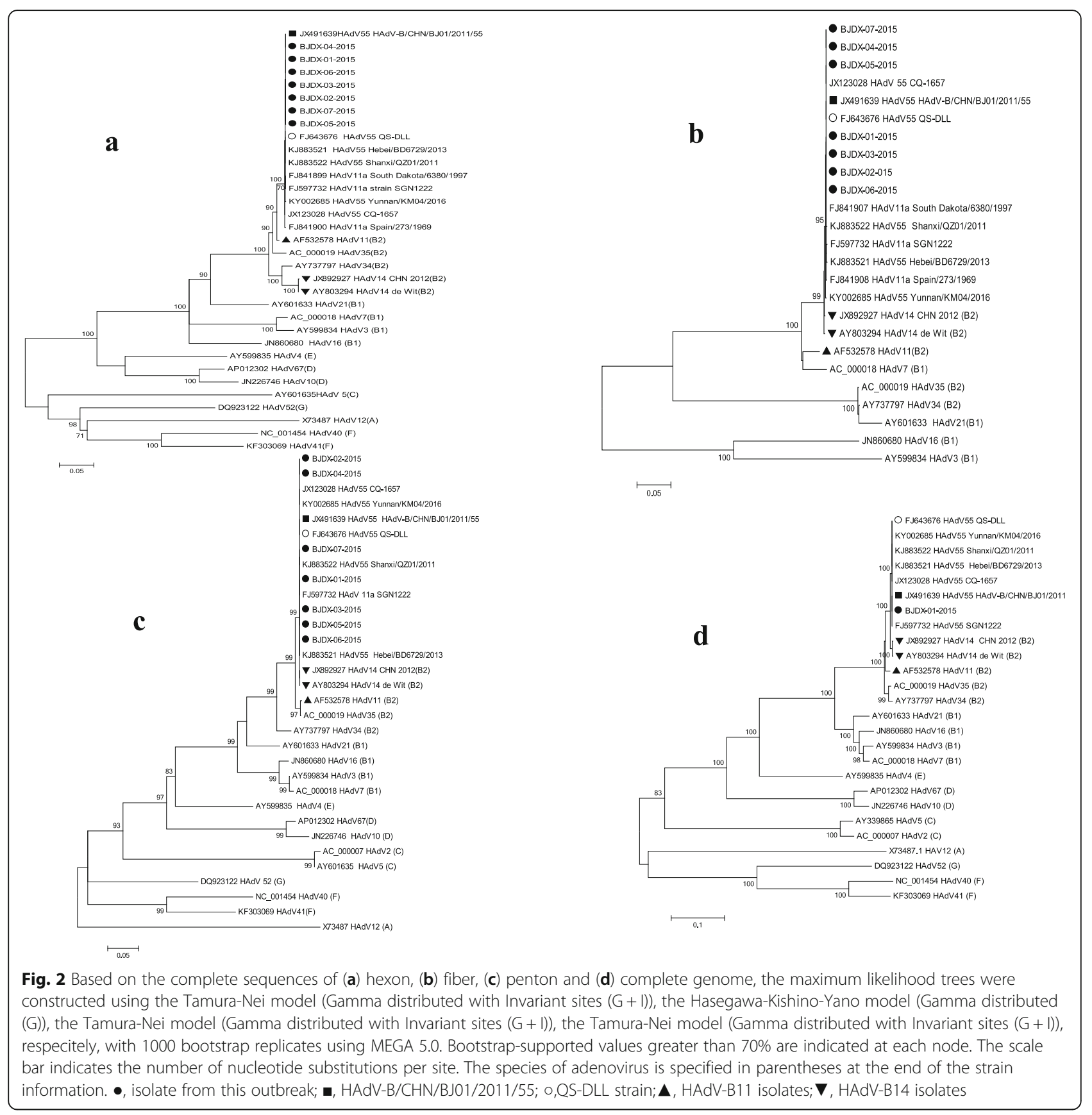

The genome of BJDX-01-2015 was 99.97\% identical to that of the HAdV-B/CHN/BJ01/2011/55 (GenBank accession number JX491639) strain, having 11 different nucleotides, and 99.89\% identical to the strain QS-DLL (GenBank accession number FJ643676), having 38 different nucleotides. BJDX-01-2015 shared $97.62 \%$ of its genome with the HAdV-B11 reference strain (GenBank accession number AF532578), and 98.89 and $98.88 \%$ of its genome with two HAdV-B14 strains (GenBank accession numbers AY803294 and JX892927; Fig. 3).
We then generated alignments between the genome sequence of strain BJDX-01-2015 and those of strains HAdV-B55, HAdV-B11, and HAdV-B14. Most of the nucleotide differences in BJDX-01-2015 relative to HAdV-B/CHN/BJ01/2011/55 (GenBank accession number JX491639) were observed in the coding region of protein VI (Fig. 4a), where we found seven nucleotide changes and six amino acid substitutions. We also found different numbers of poly " $\mathrm{T}$ " and ploy "A" tracts (Fig. 4b). 
[35], and Singapore (2005) [36]. HAdV-B55 was also identified as a re-emergent acute respiratory disease pathogen after a recent outbreak in Qishan County, Shaanxi Province, China in 2006 [9, 25]. Subsequent analysis revealed that HAdV-B55 consists of an HAdV-B14 backbone and a partial HAdV-B11 hexon gene. This re-emergent virus exhibited a neutralizing antigen epitope of HAdV-B11 and the pathogenic properties of HAdV-14. Therefore, this virus was renamed HAdV-B55 [9, 37].

In China, an increasing number of outbreaks of HAdVB55 have been reported since March 2006 [25]. Epidemic outbreaks of HAdV-B55 have occurred in military camps, schools, and even hospitals in Hebei Province (February 2012) [38], Tianjin City (January 2013) [27], Beijing (2015; this study), Guangzhou City (2016) [28], Tibet, Sichuan and Yunnan Provinces (2016) [39].

In the 2006 HAdV-B55 outbreak in China, a total of 254 patients were infected, and one died [25]. Although the virus spread quickly in the 2015 outbreak reported here, only 12 individuals were infected, including one student who developed pneumonia and was hospitalized. This suggests that the HAdV-B55 strain associated with this outbreak is not as virulent as those reported previously [25,33], yet the strain should still be considered an urgent public health threat that necessitates measures to contain or control it in order to prevent epidemics.

Unlike other outbreaks caused by HAdVs in the northern regions of China $[25,27,38]$ that occurred in the winter or spring, this outbreak in Beijing took place at the end of summer. Studies by Yu J., et al. and Liu T., et al. have reported that, although infections of HAdVs occur throughout the year, HAdV outbreak prevalence often peaks in winter and spring in the north of China and in summer and spring in the south of China [40, 41]. It is possible that HAdV outbreaks differ in their seasonality based on relative humidity and temperature. The fact that the HAdV outbreak reported here occurred in summer is thus significant because it could indicate this HAdV-B55 virus strain is capable of circulating in the climate and environmental reservoir.

The hexon, fiber, and penton genes of virus strain BJDX-01-2015 isolated in this study shared 100\% sequence identity with those of the HAdV-B55 strain HAdV-B/CHN/BJ01/2011/55 (GenBank accession number JX491639), which was isolated from a patient with severe CAP in a previous study by Bin Cao et al. at Beijing in 2011 [42, 43]. The genome of BJDX-01-2015 is most similar to that of HAdV-B/CHN/BJ01/2011/55.

In our study, the strain of BJDX-01-2015 was obtained from the index case (ID\#1), who presented with an upper respiratory infection. Furthermore most of the infected students were treated in outpatient clinics, and only one patient with non-severe pneumonia was hospitalized. The isolate of HAdV-B/CHN/BJ01/2011/55 was obtained from a patient with severe CAP in a previous study by Bin Cao et al. at Beijing [42], in which a total of 18 cases with laboratory-confirmed adenovirus infections, including the mentioned case with HAdV-B/ CHN/BJ01/2011/55, were detected in 487 CAP cases. Furthermore, HAdV-B55 was most frequently detected in the 18 cases of adenovirus pneumonia (10/18), and six of the 10 patients ultimately developed acute respiratory distress syndrome. Based on the information of the two cases, two genetic viral samples, and the two independent studies that reported laboratory-confirmed ARIS with HAdV-B55 in Beijing, the isolate of BJDX-012015 led to milder ARIs.

These findings imply that severe ARIs were not simply caused by HAdV-B55 virus strains themselves but also depend on the conditions of the hosts, such as the individual's age, general state of health, and the presence of co-morbidities or additional infections.

In this outbreak, we also found that for both the index case and the hospitalized case neutrophils increased and /or lymphocytes in the peripheral blood decreased. Studies on other respiratory viruses, such as influenza virus, respiratory syncytial virus, or human rhinovirus, have shown that an increase in neutrophils has a significant role in limiting virus replication [44, 45]. Thus, the increase in neutrophils observed here may have limited and resulted in milder clinical symptoms in this outbreak.

Most of the mutations at the amino acid level in BJDX01-2015 were observed in the coding regions of protein VI. During the replication of HAdVs, protein VI functions as an adaptor to shuttle the hexon protein to the nucleus, where virus assembly occurs [46]. Whether these variations affect the virulence of BJDX-01-2015 and are responsible for the milder clinical symptoms observed in this study requires further investigation. We also found that BJDX-01-2015 has different numbers of poly "T" and poly "A" tracts compared with other HAdV-B55, HAdVB11, and HAdV-B14 strains. The role that poly "T" and poly "A" tracts play in the evolution of HAdVs remains unclear and requires further research.

The increasing frequency of ARI outbreaks due to HAdV-B55 suggests that this re-emergent virus poses a serious threat to public health. It is therefore urgent that the local $\mathrm{CDC}$ improve epidemiological and virological surveillance of HAdV-B55.

\section{Conclusions}

We identified HAdV-B55 as the cause of a recent localized ARI outbreak. This incident was the first reported outbreak in Beijing that can be attributed to this reemergent virus. Our findings show that the risk of an HAdV-B55 epidemic should be paid more attention in Beijing, the capital of China, with a population of more than 20 million. Continuous surveillance of respiratory 
adenoviruses is an urgent need to understand the epidemiological and evolutionary features of HAdV-B55 and could also find value in an epidemiological modeling approach. We also found that the clinical laboratory data from this outbreak provides important reference for clinical diagnosis and may ultimately aid in informing the development of strategies to control and prevent respiratory tract infections caused by HAdV-B55 .

\section{Abbreviations \\ PCR: Polymerase chain reaction; ARI: Acute respiratory infection; HAdV: Human adenovirus; ITR: Inverted terminal repeat; CDC: Center for disease prevention and control; CAP: Community-acquired pneumonia; UTR: Untranslated region}

\section{Acknowledgements}

The authors thank all colleagues in the Beijing CDC for their help in molecular detection and whole-genome analysis. They also thank the technicians of the Daxing CDC of Beijing for their excellent technical assistance with the epidemiological investigation and with the initial laboratory diagnosis.

\section{Authors' contributions}

All authors made significant contributions to the data, analysis, and drafting of this manuscript and approved the final submitted version. GL wrote the manuscript. GL, XP and RL performed genomic analysis. YL, DZ and JZ conducted the diagnostic experiments. ZW, XW, YS and LZ participated in collecting information of this outbreak. PY and QW helped review this manuscript. All authors have read and approved the manuscript.

\section{Funding}

This study was supported by the Research on Early Detection, Genetic Evolution and Risk Assessment for Novel Influenza Virus by Capital's Funds for Health Improvement and Research (2018-1-1012).

\section{Availability of data and materials}

The datasets used and/or analyzed in the current study are available from the corresponding author upon reasonable request.

\section{Ethics approval and consent to participate}

This study was approved by the Ethics Committee of Beijing CDC. Written informed consent was obtained from all the participants or the guardians if participants were under 16 years of age.

\section{Consent for publication}

Not applicable.

\section{Competing interests}

The authors declare no competing interests.

\section{Author details}

${ }^{1}$ Institute for Infectious Disease and Endemic Disease Control, Beijing Center for Disease Prevention and Control, Beijing Research Center for Preventive Medicine, 16\# He Ping Li Middle Street, Dongcheng District, Beijing 100013, China. ${ }^{2}$ Daxing District Center for Disease Prevention and Control, Beijing 102600, China.

Received: 29 November 2019 Accepted: 14 July 2020

Published online: 23 July 2020

\section{References}

1. Lynch JP 3rd, Kajon AE. Adenovirus: epidemiology, global spread of novel serotypes, and advances in treatment and prevention. Semin Respir Crit Care Med. 2016;37(4):586-602.

2. Jones MS 2nd, Harrach B, Ganac RD, Gozum MM, Dela Cruz WP, Riedel B, et al. New adenovirus species found in a patient presenting with gastroenteritis. J Virol. 2007;81(11):5978-84.
3. Engelmann I, Madisch I, Pommer H, Heim A. An outbreak of epidemic keratoconjunctivitis caused by a new intermediate adenovirus 22/H8 identified by molecular typing. Clin Infect Dis. 2006;43(7):e64-6.

4. Alharbi S, Van Caeseele P, Consunji-Araneta R, Zoubeidi T, Fanella S, Souid AK, et al. Epidemiology of severe pediatric adenovirus lower respiratory tract infections in Manitoba, Canada, 1991-2005. BMC Infect Dis. 2012:12:55.

5. Jain S, Self WH, Wunderink RG, Fakhran S, Balk R, Bramley AM, et al. Community-acquired pneumonia requiring hospitalization among U.S. adults. N Engl J Med. 2015;373(5):415-27.

6. Rowe WP, Huebner RJ, Gilmore LK, Parrott RH, Ward TG. Isolation of a cytopathogenic agent from human adenoids undergoing spontaneous degeneration in tissue culture. Proc Soc Exp Biol Med. 1953;84(3):570-3.

7. Ghebremedhin B. Human adenovirus: viral pathogen with increasing importance. Eur J Microbiol Immunol (Bp). 2014;4(1):26-33.

8. Kajon AE, Lamson DM, St George K. Emergence and re-emergence of respiratory adenoviruses in the United States. Curr Opin Virol. 2019;14(34): 63-9.

9. Walsh MP, Seto J, Jones MS, Chodosh J, Xu W, Seto D. Computational analysis identifies human adenovirus type 55 as a re-emergent acute respiratory disease pathogen. J Clin Microbiol. 2010;48(3):991-3.

10. Walsh MP, Seto J, Liu EB, Dehghan S, Hudson NR, Lukashev AN, Ivanova O, Chodosh J, Dyer DW, Jones MS, Seto D. Computational analysis of two species $C$ human adenoviruses provides evidence of a novel virus. J Clin Microbiol. 2011;49(10):3482-90.

11. Matsushima $Y$, Shimizu H, Kano A, Nakajima E, Ishimaru $Y$, Dey SK, et al. Novel human adenovirus strain, Bangladesh. Emerg Infect Dis. 2012;18(5): 846-8.

12. Davison AJ, Benko M, Harrach B. Genetic content and evolution of adenoviruses. J Gen Virol. 2003;84(Pt 11):2895-908.

13. Saha B, Wong CM, Parks RJ. The adenovirus genome contributes to the structural stability of the virion. Viruses. 2014;6(9):3563-83.

14. Tebruegge $M$, Curtis N. Adenovirus: an overview for pediatric infectious diseases specialists. Pediatr Infect Dis J. 2012;31(6):626-7.

15. James L, Vernon MO, Jones RC, Stewart A, Lu X, Zollar LM, et al. Outbreak of human adenovirus type 3 infection in a pediatric long-term care facility-Illinois, 2005. Clin Infect Dis. 2007:45(4):416-20.

16. Guo L, Gonzalez R, Zhou H, Wu C, Vernet G, Wang Z, Wang J. Detection of three human adenovirus species in adults with acute respiratory infection in China. Eur J Clin Microbiol Infect Dis. 2012;31(6):1051-8.

17. Ou ZY, Zeng QY, Wang FH, Xia HM, Lu JP, Xia JQ, et al. Retrospective study of adenovirus in autopsied pulmonary tissue of pediatric fatal pneumonia in South China. BMC Infect Dis. 2008:8:122

18. Abd-Jamil J, Teoh BT, Hassan EH, Roslan N, Abubakar S. Molecular identification of adenovirus causing respiratory tract infection in pediatric patients at the University of Malaya Medical Center. BMC Pediatr. 2010;10:46

19. Hong JY, Lee HJ, Piedra PA, Choi EH, Park KH, Koh YY, et al. Lower respiratory tract infections due to adenovirus in hospitalized Korean children: epidemiology, clinical features, and prognosis. Clin Infect Dis. 2001;32(10):1423-9.

20. Yu X, Lu R, Wang Z, Zhu N, Wang W, Julian D, et al. Etiology and clinical characterization of respiratory virus infections in adult patients attending an emergency department in Beijing. PLoS One. 2012;7(2):e32174.

21. Wo Y, Lu QB, Huang DD, Li XK, Guo CT, Wang HY, et al. Epidemical features of HAdV-3 and HAdV-7 in pediatric pneumonia in Chongqing, China. Arch Virol. 2015;160(3):633-8.

22. Xie L, Yu XF, Sun Z, Yang XH, Huang RJ, Wang J, et al. Two adenovirus serotype 3 outbreaks associated with febrile respiratory disease and pharyngoconjunctival fever in children under 15 years of age in Hangzhou, China, during 2011. J Clin Microbiol. 2012;50(6):1879-88.

23. Tang L, Wang L, Tan X, Xu W. Adenovirus serotype 7 associated with a severe lower respiratory tract disease outbreak in infants in Shaanxi Province, China. Virol J. 2011:8:23

24. Cheng J, Qi X, Chen D, Xu X, Wang G, Dai Y, et al. Epidemiology and transmission characteristics of human adenovirus type 7 caused acute respiratory disease outbreak in military trainees in East China. Am J Transl Res. 2016;8(5):2331-42

25. Zhu Z, Zhang $Y, X u S$, et al. Outbreak of acute respiratory disease in China caused by B2 species of adenovirus type 11. J Clin Microbiol. 2009;47(3): 697-703.

26. Salama M, Amitai Z, Amir N, Gottesman-Yekutieli T, Sherbany H, Drori Y, et al. Outbreak of adenovirus type 55 infection in Israel. J Clin Virol. 2016;78: $31-5$. 
27. Li X, Kong M, Su X, Zou M, Guo L, Dong X, et al. An outbreak of acute respiratory disease in China caused by human adenovirus type B55 in a physical training facility. Int J Infect Dis. 2014;28:117-22.

28. Yi L, Zou L, Lu J, Kang M, Song Y, Su J, et al. A cluster of adenovirus type B55 infection in a neurosurgical inpatient department of a general hospital in Guangdong, China. Influenza Other Respir Viruses. 2017;11(4):328-36.

29. Shi W, Cui S, Gong C, Zhang T, Yu X, Li A, et al. Prevalence of human parainfluenza virus in patients with acute respiratory tract infections in Beijing, 2011-2014. Influenza Other Respir Viruses. 2015;9(6):305-7.

30. Kim C, Ahmed JA, Eidex RB, Nyoka R, Waiboci LW, Erdman D, et al. Comparison of nasopharyngeal and oropharyngeal swabs for the diagnosis of eight respiratory viruses by real-time reverse transcription-PCR assays. PLoS One. 2011;6(6):e21610.

31. Chen M, Zhu Z, Huang F, Liu D, Zhang T, Ying D, et al. Adenoviruses associated with acute respiratory diseases reported in Beijing from 2011 to 2013. PLoS One. 2015;10(3):e0121375.

32. Zhang D, Lou X, Yan H, Pan J, Mao H, Tang H, et al. Metagenomic analysis of viral nucleic acid extraction methods in respiratory clinical samples. BMC Genomics. 2018;19(1):773.

33. Cao B, Huang GH, Pu ZH, Qu JX, Yu XM, Zhu Z, et al. Emergence of community-acquired adenovirus type 55 as a cause of community-onset pneumonia. Chest. 2014;145(1):79-86.

34. Hierholzer JC, Pumarola A, Rodriguez-Torres A, Beltran M. Occurrence of respiratory illness due to an atypical strain of adenovirus type 11 during a large outbreak in Spanish military recruits. Am J Epidemiol. 1974;99(6):43442.

35. Chmielewicz B, Benzler J, Pauli G, Krause G, Bergmann F, Schweiger B. Respiratory disease caused by a species B2 adenovirus in a military camp in Turkey. J Med Virol. 2005;77(2):232-7.

36. Kajon AE, Dickson LM, Metzgar D, Houng HS, Lee V, Tan BH. Outbreak of febrile respiratory illness associated with adenovirus 11a infection in a Singapore military training CAMP. J Clin Microbiol. 2010;48(4):1438-41.

37. Seto D, Jones MS, Dyer DW, Chodosh J. Characterizing, typing, and naming human adenovirus type 55 in the era of whole genome data. J Clin Virol. 2013;58(4):741-2.

38. Lu QB, Tong YG, Wo Y, Wang HY, Liu EM, Gray GC, et al. Epidemiology of human adenovirus and molecular characterization of human adenovirus 55 in China, 2009-2012. Influenza Other Respir Viruses. 2014;8(3):302-8.

39. Wang W, Liu Y, Zhou Y, Gu L, Zhang L, Zhang X, et al. Whole-genome analyses of human adenovirus type 55 emerged in Tibet, Sichuan and Yunnan in China, in 2016. PLoS One. 2017;12(12):e0189625.

40. Yu J, Xie Z, Zhang T, Lu Y, Fan H, Yang D, et al. Comparison of the prevalence of respiratory viruses in patients with acute respiratory infections at different hospital settings in North China, 2012-2015. BMC Infect Dis. 2018;18(1):72.

41. Liu T, Li Z, Zhang S, Song S, Julong W, Lin Y, et al. Viral etiology of acute respiratory tract infections in hospitalized children and adults in Shandong Province, China. Virol J. 2015;12:168.

42. Gu L, Liu Z, Li X, Qu J, Guan W, Liu Y, Song S, Yu X, et al. Severe community-acquired pneumonia caused by adenovirus type 11 in immunocompetent adults in Beijing. J Clin Virol. 2012;54(4):295-301.

43. Zhang Q, Seto D, Cao B, Zhao S, Wan C. Genome sequence of human adenovirus type 55 , a re-emergent acute respiratory disease pathogen in China. J Virol. 2012;86(22):12441-2.

44. Tate MD, Brooks AG, Reading PC. The role of neutrophils in the upper and lower respiratory tract during influenza virus infection of mice. Respir Res. 2008;9:57.

45. Bataki EL, Evans GS, Everard ML. Respiratory syncytial virus and neutrophil activation. Clin Exp Immunol. 2005;140(3):470-7.

46. Moyer CL, Besser ES, Nemerow GR. A single maturation cleavage site in adenovirus impacts cell entry and capsid assembly. J Virol. 2015;90(1):52132.

\section{Publisher's Note}

Springer Nature remains neutral with regard to jurisdictional claims in published maps and institutional affiliations.

\section{Ready to submit your research? Choose BMC and benefit from:}

- fast, convenient online submission

- thorough peer review by experienced researchers in your field

- rapid publication on acceptance

- support for research data, including large and complex data types

- gold Open Access which fosters wider collaboration and increased citations

- maximum visibility for your research: over $100 \mathrm{M}$ website views per year

At BMC, research is always in progress.

Learn more biomedcentral.com/submissions 